\title{
OPTIMAL PASSIVE STRUCTURAL CONTROL UNDER EXTREME EARTHQUAKE EXCITATIONS USING A COMBINED PENDULUM TUNED MASS DAMPER
}

\author{
Abanoub G. Kamel', Remon M. Basily ${ }^{2}$ \\ ${ }^{1}$ Department of Engineering Mathematics and Physics, Faculty of Engineering, Alexandria University \\ Alexandria, Egypt \\ ${ }^{2}$ Department of Mechanical Engineering, École Centrale de Nantes \\ Nantes, France \\ abanoub.george@alexu.edu.eg,remon.basily@eleves.ec-nantes.fr
}

Received: 13 July 2021; Accepted: 13 November 2021

\begin{abstract}
Many engineering applications utilize passive Tuned Mass Dampers (TMDs) in several engineering applications because of their simplicity, readiness, and their ability in attenuating structural vibrations exposed to mild or extreme earthquake excitations. The main aim of this work is to find the optimum values of the system parameters after attaching a three degree of freedom Combined Pendulum Tuned Mass Damper (3-DOF CPTMD) to the main structure to investigate if the proposed solution will assist in reducing the amplitude of the vibration. Three optimization search techniques are utilized, and the best optimum method is determined. Moreover, the structural system was modelled mathematically to get the governing motion equations, and the system was put into state-space format before being simulated using a homemade MATLAB ${ }^{\odot}$ code. Additionally, it is found that the proposed 3-DOF CPTMD is very effective in dampening the structural vibrations under various earthquake excitations (including extreme conditions).
\end{abstract}

MSC 2010: 13P25, 65K10, 70J35, 74H45

Keywords: passive structural control, earthquake excitations, offshore platform, Tuned Mass Damper, mathematical modelling, MATLAB ${ }^{\odot}$

\section{Introduction}

These days, novel active control of vibrations is commonly used to suppress the amplitude of structural vibrations, also, the classic passive vibration control is still utilized, because it is simple and ready. One well-known kind is the tuned mass damper (TMD), which mainly consists of a mass, a spring, and a viscous damper. Moreover, TMDs have been extensively investigated by several researchers for more than a century, and their great dampening capabilities, have been successfully installed in a plethora of various structures, for instance, buildings [1], offshore platforms [2], bridges [3], trains [4], wind turbines [5], chimneys [6], submerged pipelines [7], and even in space mirrors [8]. 
Yang et al. [9] presented an outline of a benchmark problem for the vibration control of wind-excited tall buildings. It is a 76-story building with a total height of 306 meters. They used the active control method to test the control design. Moreover, they introduced the control requirements as well as the assessment criteria for the proposed active control. Rana and Soong [10] investigated the detuning impact on the performance of TMD utilizing time-history as well as steady-state harmonic excitation analysis. Additionally, the impact of numerical tuning is examined. They studied TMD design for a single degree of freedom (SDOF) and a specific mode of a multi-degree of freedom (MDOF) structure. Furthermore, they studied the usage of multi-tuned mass dampers (MTMD).

Additionally, Zuo and Nayfeh [11] introduced an effective numerical methodology dependent on the descent-subgradient technique in order to amplify the damping of the minimum mode for MTMDs in a specific frequency range. Study cases are given to represent the effectiveness of the proposed technique and the damping capability of MTMDs. They presented the results of an optimized 2-DOF TMD to attenuate the initial two modes of a free-free beam. Pourzeynali et al. [12] outlined the shared usage of fuzzy logic control as well as genetic algorithms to design the active TMD control and optimize its parameters in order to obtain the best outcomes for vibration dampening of a structure under earthquake loading. The proposed technique is applied to an 11-floor building, and they found that the use of the fuzzy logic control and genetic algorithms is efficient.

On the other hand, Hrovat et al. [13] presented a semi-active TMD in order to control wind excited vibrations in high-rise structures. Their suggested control method utilizes a limited quantity of external power for damping modulation. The net outcome is what might be compared to a passive TMD with time-dependent parameters which are controlled hydraulically. Moreover, they made several simulations that show their suggested control method is better than a passive TMD and similar to an active TMD. Similarly, Symans and Constantinou [14] provided a review that focuses on the descriptions of the dynamic behaviour of semi-active control systems with a correlation with comparison to passive and active control systems as well. They showed that semi-active control systems have the potential for improving the response of structures induced to seismic load.

However, Lazar et al. [15] proposed an innovative type of passive control that depends on the inerter to lessen base-induced vibrations inside a multi-story building. Their outcomes showed that a phenomenal degree of vibration suppression can be accomplished. Li [16] considered MTMDs for dampening unwanted structural vibration. He explored the optimum parameters of the MTMD by applying a numerical searching strategy, and he discovered that the optimal MTMD with variable mass is more efficient than the optimal MTMD with constant mass and the optimal single TMD with equivalent mass.

Ata and Kamel $[17,18]$ introduced and investigated the impact of attaching a 2-DOF Combined Pendulum Tuned Mass Damper (CPTMD) on a SDOF basic system subjected to earthquake vibrations, to decrease its response. They conducted a parametric study with various estimations of the system constants and assessed 
the structure performance, by considering the settling time, first peak amplitude, and overshoot. Furthermore, the CPTMD's ability to dampen the oscillation soared because of increasing the damper coefficient of the CPTMD, with a percentage reduction in the settling time of $(79.42 \%)$ which demonstrated the effectiveness of the CPTMD. Nevertheless, the present study will continue to improve the CPTMD system proposed by Ata and Kamel $[17,18]$ in order to find the optimum values of the parameters of the CPTMD that will further reduce the settling time of the main vibrating system significantly.

\section{Problem modelling and formulation}

Every offshore jacket platform does a significant job in the oil recovery field. Moreover, each offshore jacket platform typically comprises three main sections which are the living section, the working section, and the jackets section. Also, the offshore jacket platform can be modelled as a SDOF structure where the mass of the upper section is prevailing to the entire structure.

Now, consider the main vibrating system that consists of a mass $\left(m_{1}\right)$, spring with stiffness $\left(k_{1}\right)$, and damper with damping coefficient $\left(c_{1}\right)$ as shown in Figure 1. The system is at rest for $t<0$, and the displacements $\left(x_{1}, x_{2}\right.$, and $\left.x_{3}\right)$ are measured from their respective equilibrium positions before the input excitation of an induced ground acceleration $\left(a_{g}\right)$ from an earthquake acts on the system at $t \geq 0$. A 3-DOF CPTMD is attached to the main system which also consists of large mass $\left(m_{2}\right)$, spring with stiffness $\left(k_{2}\right)$, damper with damping coefficient $\left(c_{2}\right)$, small mass $\left(m_{3}\right)$, another two identical springs with stiffness $\left(k_{3}\right)$ for each, besides a compound pendulum consisting of a bob mass $\left(m_{4}\right)$ that is attached to the end of a homogeneous pendulum link of mass $\left(m_{5}\right)$ and a length $(L)$ and makes an angle $(\theta)$ with the vertical line. Moreover, the weight of the pendulum link acts at its geometric centre. Moreover, the compound pendulum itself is attached to the second mass $\left(m_{2}\right)$ through a torsion spring with stiffness $\left(k_{4}\right)$ and a rotational damper with a damping coefficient $\left(c_{3}\right)$ as shown in Figure 1.

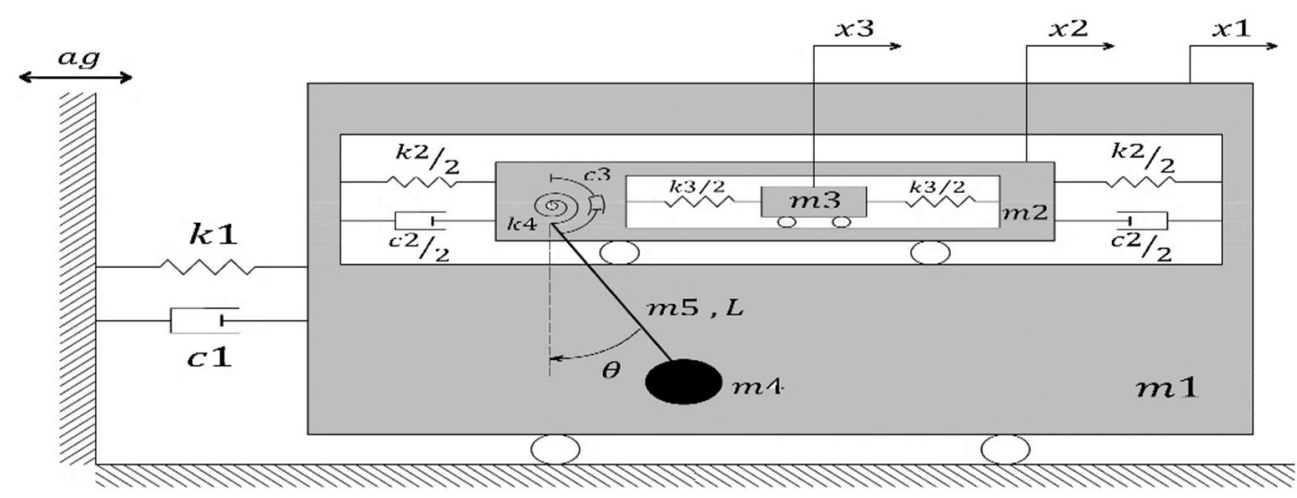

Fig. 1. A SDOF simplified offshore platform equipped with a 3-DOF CPTMD 


\section{Mathematical modelling}

The equations of motion can be derived using Lagrange's Equation from Han and Benaroya [19] as follows:

$$
\frac{\mathrm{d}}{\mathrm{dt}}\left(\frac{\partial T}{\partial \dot{q}_{i}}\right)-\frac{\partial T}{\partial q_{i}}+\frac{\partial R}{\partial \dot{q}_{i}}+\frac{\partial U}{\partial q_{i}}=Q_{i}
$$

where $q$ is the generalized coordinates and $Q$ is the generalized forces associated with the generalized coordinates. The kinetic energy and the potential energy of the whole system are given by

$$
\begin{gathered}
T=\frac{1}{2} m_{1}{\dot{x_{1}}}^{2}+\frac{1}{2}\left(m_{2}+m_{4}+m_{5}\right){\dot{x_{2}}}^{2}+\frac{1}{2} m_{3}{\dot{x_{3}}}^{2}+ \\
\frac{1}{2}\left(m_{4} L^{2}+\frac{1}{4} m_{5} L^{2}+J_{C G}\right) \dot{\theta}^{2}+\frac{1}{2}\left(2 m_{4}+m_{5}\right) L \cos (\theta) \dot{x_{2}} \dot{\theta} \\
U=\frac{1}{2} k_{1} x_{1}{ }^{2}+\frac{1}{2} k_{2}\left(x_{1}-x_{2}\right)^{2}+\frac{1}{2}\left(2 k_{3}\right)\left(x_{2}-x_{3}\right)^{2}+\frac{1}{2} k_{4} \theta^{2}+ \\
\left(m_{4}+\frac{1}{2} m_{5}\right) \operatorname{g} L(1-\cos (\theta))
\end{gathered}
$$

Where $g$ is the gravitational acceleration, and the mass moment of inertia of the pendulum is $J_{C G}=\frac{1}{12} m_{5} L^{2}$. While the dissipative energy is given by

$$
R=\frac{1}{2} c_{1}{\dot{x_{1}}}^{2}+\frac{1}{2} c_{2}\left(\dot{x}_{1}-\dot{x}_{2}\right)^{2}+\frac{1}{2} c_{3} \dot{\theta}^{2}
$$

Equation (1) will be utilized to derive the four equations of motion related to the four generalized coordinates $\left(x_{1}, x_{2}, x_{3}\right.$, and $\left.\theta\right)$. After some algebraic manipulation, the four equations of motion can be written as:

$$
\begin{gathered}
m_{1} \ddot{x}_{1}+\left(c_{1}+c_{2}\right) \dot{x}_{1}+\left(k_{1}+k_{2}\right) x_{1}-c_{2} \dot{x}_{2}-k_{2} x_{2}=m_{1} a_{g} \\
\left(m_{2}+m_{4}+m_{5}\right) \ddot{x}_{2}+c_{2} \dot{x}_{2}+\left(k_{2}+2 k_{3}\right) x_{2}-c_{2} \dot{x}_{1}-k_{2} x_{1}- \\
2 k_{3} x_{3}+\frac{1}{2}\left(2 m_{4}+m_{5}\right) L \cos (\theta) \ddot{\theta}-\frac{1}{2}\left(2 m_{4}+m_{5}\right) L \sin (\theta) \dot{\theta}^{2}= \\
\left(m_{2}+m_{4}+m_{5}\right) a_{g} \\
m_{3} \ddot{x}_{3}+2 k_{3} x_{3}-2 k_{3} x_{2}=m_{3} a_{g} \\
\left(m_{4} L^{2}+\frac{1}{4} m_{5} L^{2}+J_{C G}\right) \ddot{\theta}+c_{3} \dot{\theta}+k_{4} \theta+\left(m_{4}+\frac{1}{2} m_{5}\right) \mathrm{g} L \sin (\theta)+ \\
\frac{1}{2}\left(2 m_{4}+m_{5}\right) L \cos (\theta) \ddot{x}_{2}=0
\end{gathered}
$$




\subsection{Linearization of the equations of motion}

Before the model linearization, a hypothesis for simple analysis is assumed; the rotation angle will be kept small, and order of magnitude analysis which was assumed by Asad et al. [20] is performed as follows:

$$
\sin (\theta) \approx \theta, \cos (\theta) \approx 1, \dot{\theta}^{2} \approx 0
$$

So that the equations of motion became:

$$
\begin{gathered}
m_{1} \ddot{x}_{1}+\left(c_{1}+c_{2}\right) \dot{x}_{1}+\left(k_{1}+k_{2}\right) x_{1}-c_{2} \dot{x}_{2}-k_{2} x_{2}=m_{1} a_{g} \\
\left(m_{2}+m_{4}+m_{5}\right) \ddot{x}_{2}+c_{2} \dot{x}_{2}+\left(k_{2}+2 k_{3}\right) x_{2}-c_{2} \dot{x}_{1}-k_{2} x_{1}-2 k_{3} x_{3}+ \\
\frac{1}{2}\left(2 m_{4}+m_{5}\right) L \ddot{\theta}=\left(m_{2}+m_{4}+m_{5}\right) a_{g} \\
m_{3} \ddot{x}_{3}+2 k_{3} x_{3}-2 k_{3} x_{2}=m_{3} a_{g} \\
\left(m_{4} L^{2}+\frac{1}{4} m_{5} L^{2}+J_{C G}\right) \ddot{\theta}+c_{3} \dot{\theta}+\left(k_{4}+\left(m_{4}+\frac{1}{2} m_{5}\right) g L\right) \theta+ \\
\frac{1}{2}\left(2 m_{4}+m_{5}\right) L \ddot{x}_{2}=0
\end{gathered}
$$

After simplification and preparation of equations of motion for state-space representation, one can obtain the final form of equations of motion as follows:

$$
\begin{gathered}
\ddot{x}_{1}=\frac{1}{m_{1}}\left[m_{1} a_{g}-\left(c_{1}+c_{2}\right) \dot{x}_{1}-\left(k_{1}+k_{2}\right) x_{1}+c_{2} \dot{x}_{2}+k_{2} x_{2}\right] \\
\ddot{x}_{2}=A_{1}\left[\left(m_{2}+m_{4}+m_{5}\right) a_{g}+c_{2} \dot{x}_{1}+k_{2} x_{1}-c_{2} \dot{x}_{2}-\right. \\
\left.\left(k_{2}+2 k_{3}\right) x_{2}+2 k_{3} x_{3}\right]+A_{2}\left[c_{3} \dot{\theta}+A_{4} \theta\right] \\
\ddot{x}_{3}=\frac{1}{m_{3}}\left[m_{3} a_{g}-2 k_{3} x_{3}+2 k_{3} x_{2}\right] \\
\ddot{\theta}=\frac{1}{A_{3}}\left[-c_{3} \dot{\theta}-A_{4} \theta-A_{5}\left[\left(m_{2}+m_{4}+m_{5}\right) a_{g}+c_{2} \dot{x}_{1}+\right.\right. \\
\left.\left.k_{2} x_{1}-c_{2} \dot{x}_{2}-\left(k_{2}+2 k_{3}\right) x_{2}+2 k_{3} x_{3}\right]\right]
\end{gathered}
$$

Where the terms $\left(A_{1}, A_{2}, A_{3}, A_{4}\right.$, and $\left.A_{5}\right)$ are defined as follows:

$$
\begin{gathered}
A_{1}=\left(\frac{1}{\left(m_{2}+m_{4}+m_{5}\right)}+\frac{\left(2 m_{4}+m_{5}\right)^{2} L^{2}}{4\left(m_{2}+m_{4}+m_{5}\right)^{2} A_{3}}\right) \\
A_{2}=\left(\frac{\frac{1}{2}\left(2 m_{4}+m_{5}\right) L}{\left(m_{2}+m_{4}+m_{5}\right) A_{3}}\right)
\end{gathered}
$$




$$
\begin{gathered}
A_{3}=\left(m_{4} L^{2}+\frac{1}{4} m_{5} L^{2}+J_{C G}-\frac{\left(2 m_{4}+m_{5}\right)^{2} L^{2}}{4\left(m_{2}+m_{4}+m_{5}\right)}\right) \\
A_{4}=\left(k_{4}+\left(m_{4}+\frac{1}{2} m_{5}\right) \mathrm{g} L\right) \\
A_{5}=\left(\frac{\left(2 m_{4}+m_{5}\right) L}{2\left(m_{2}+m_{4}+m_{5}\right)}\right)
\end{gathered}
$$

In State-Space format, the modelling equations: (14), (15), (16), and (17) are represented as:

$$
\begin{aligned}
& \dot{y}(t)=A y(t)+B a_{g} \\
& x(t)=C y(t)+D a_{g}
\end{aligned}
$$

Where $y(t)$ is the state vector describing displacements and velocities of the main system (structure) as well as the CPTMD, while $x(t)$ is the state vector describing the displacements of the main system (structure) and the displacements as well as the swinging angle of the CPTMD (the required output or the system response). The State Space format can be written in matrix form as:

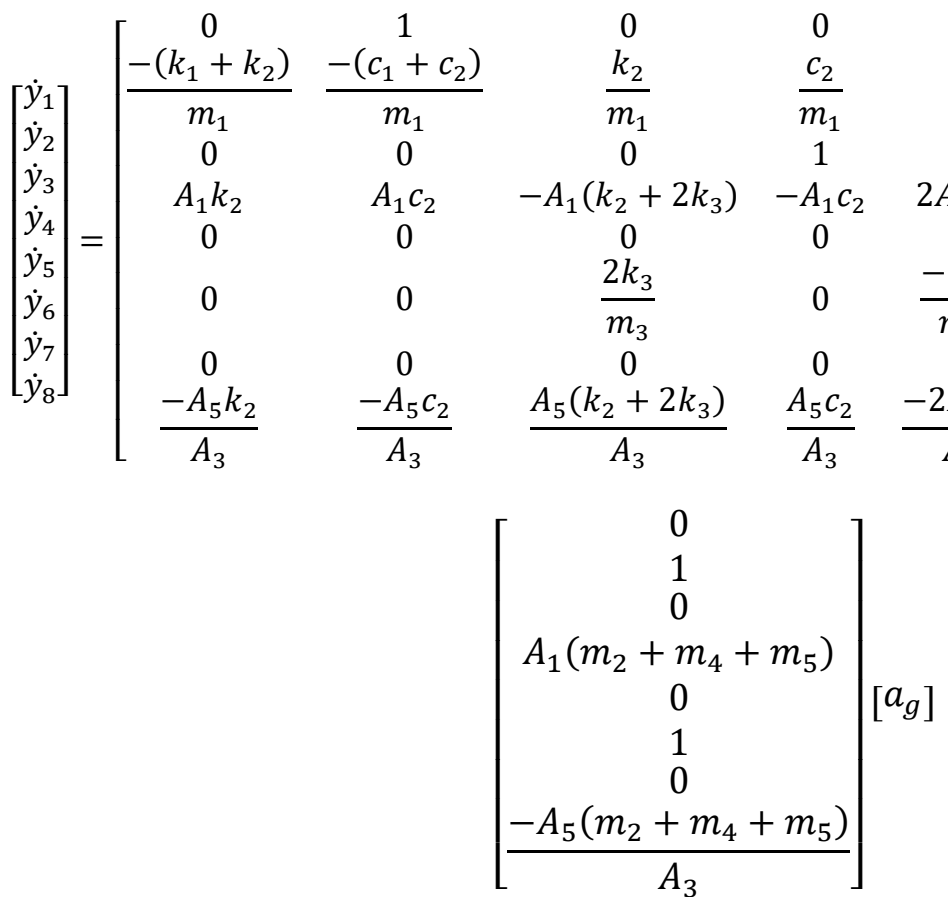




$$
\left[\begin{array}{l}
x_{1} \\
x_{2} \\
x_{3} \\
\theta
\end{array}\right]=\left[\begin{array}{llllllll}
1 & 0 & 0 & 0 & 0 & 0 & 0 & 0 \\
0 & 0 & 1 & 0 & 0 & 0 & 0 & 0 \\
0 & 0 & 0 & 0 & 1 & 0 & 0 & 0 \\
0 & 0 & 0 & 0 & 0 & 0 & 1 & 0
\end{array}\right]\left[\begin{array}{l}
y_{1} \\
y_{2} \\
y_{3} \\
y_{4} \\
y_{5} \\
y_{6} \\
y_{7} \\
y_{8}
\end{array}\right]
$$

The previous equations, (19) and (20) were solved by MATLAB $^{\odot}$ code.

\section{Numerical simulation}

First, a study is conducted on the main existing system (offshore platform) under the excitation of an induced ground acceleration $\left(a_{g}\right)$ from an earthquake before attaching the proposed solution which is the 3-DOF CPTMD, to see the behaviour of the offshore platform and to measure its original response. Then the 3-DOF CPTMD is attached to the system to enhance its capability against vibrations. In order to evaluate the structure response; the factors listed in Table 1 will remain constant throughout the study, where $a_{g}$ is varied according to mild [21] as well as extreme [22] earthquake excitations, respectively.

Furthermore, three numerical search methods are known as the golden-section search [23], the dichotomous search [24], and the ternary search [25]. The three optimization approaches are based on the consideration of all parameters of the 3-DOF CPTMD on each other and on the system to calculate the optimum value of the settling time. The three optimization techniques are implemented by an iterative solver that performs several trials by selecting values for each parameter and calculate the settling time after solving equations (19) and (20). However, the convergence criterion for the iterative solver is taken to be equal to $10^{-5}$ for the three numerical optimization methods.

The computations have been conducted on an HP EliteBook 840 G3 Laptop, Intel ${ }^{\circledR}$ Core $^{\mathrm{TM}}$ i5-5300U with $8 \mathrm{~GB}$ DDR3 $1600 \mathrm{MHz}$ RAM and $2.3 \mathrm{GHz} \mathrm{CPU}$ using the MATLAB ${ }^{\odot}$ software.

Table 1 . The design parameters used in this study

\begin{tabular}{|l|c|c|}
\hline \multicolumn{1}{|c|}{ The design parameter } & The value & The Reference \\
\hline$m_{1}[\mathrm{~kg}]$ & 3127000 & {$[2]$} \\
\hline$k_{1}[\mathrm{kN} / \mathrm{m}]$ & 93436 & {$[2]$} \\
\hline$c_{1}[\mathrm{kN} \cdot \mathrm{s} / \mathrm{m}]$ & 1367 & {$[2]$} \\
\hline$a_{g}\left[\mathrm{~m} / \mathrm{s}^{2}\right]$ & $0.36 \mathrm{~g}$ & {$[21]$} \\
\hline$a_{g}\left[\mathrm{~m} / \mathrm{s}^{2}\right]$ & $3 \mathrm{~g}$ & {$[22]$} \\
\hline
\end{tabular}




\subsection{For mild earthquake excitation at $a_{g}=0.36 \mathrm{~g}$}

The comparison between the three optimization approaches for a seismic loading at $a_{g}=0.36 \mathrm{~g}$ is presented in Table 2. It can be seen from Table 2 that the peak amplitude calculated by the three methods is nearly similar. On the contrary, the smallest overshot percentage is found in the ternary search while the greatest value is found in the dichotomous search. Moreover, the settling time calculated by the ternary as well as the golden section approaches, as observed in Table 2, are very close and are better than that which is calculated by the dichotomous approach. Nevertheless, the golden-section search approach consumes higher computational time as well as iterations in comparison to the other approaches.

Table 2. Comparison of the system response between the three optimization search approaches at $a_{g}=0.36 \mathrm{~g}$

\begin{tabular}{|l|c|c|c|}
\hline \multicolumn{1}{|c|}{ Criterion } & Ternary search & Dichotomous search & Golden-section search \\
\hline Peak amplitude $[\mathrm{m}]$ & 0.068 & 0.066 & 0.067 \\
\hline Overshot $[\%]$ & 62.54 & 81.87 & 70.41 \\
\hline Settling time $[\mathrm{s}]$ & 14 & 16.2 & 14.44 \\
\hline Computational time $[\mathrm{s}]$ & 32.32 & 4.2 & 61.14 \\
\hline No. of Iterations & 44 & 14 & 197 \\
\hline
\end{tabular}

The optimum Parameters' values of the components of the attached 3-DOF CPTMD for the three numerical optimization methods are shown in Table 3. In order to determine the approach that has the best performance compared to its optimum values, the approach will depend on the added masses because it is not desirable to increase the total mass of the platform for safety reasons, and it will also depend on the length of the pendulum link for the construction feasibility and its applicability.

Therefore, according to the tabulated data in Table 3, and in terms of the total amount of the added masses, the dichotomous search has the lowest masses, but it requires a very long pendulum link which is not practical. However, the optimum values obtained from the golden-section search are better than those of the other approaches due to the suitable amount of the used masses as well as the smallest pendulum length which is more applicable in the industrial field and with higher efficiency. Hence, the golden-section search is demonstrated to be the optimum optimization technique and will be used in the remaining study.

It is observed from Figure 2 that the amplitude of the maximum value of the swinging angle $(\theta)$ of the pendulum is approximately $\left(0.18 \mathrm{rad}=10.32^{\circ}\right)$ and diminished with time. This agrees very well with the assumptions made in equation (9).

It can be clearly seen from Figure 3 that after using the golden-section search optimization approach and its optimum values for the attached 3-DOF CPTMD, 
the peak amplitude of the main structure reduced from $0.225 \mathrm{~m}$ to only $0.067 \mathrm{~m}$ with a percentage reduction of nearly $70 \%$ which demonstrates the importance as well as the effectiveness of using the proposed solution (the 3-DOF CPTMD) in effectively attenuating the vibrations of the oil recovery offshore jacket platform.

Table 3. The optimum Parameters' values of the components of the attached 3-DOF CPTMD for the three approaches at $a_{g}=0.36 \mathrm{~g}$ for the shown range of searching

\begin{tabular}{|c|c|c|c|c|}
\hline Parameters & $\begin{array}{l}\text { Ternary } \\
\text { search }\end{array}$ & $\begin{array}{l}\text { Dichotomous } \\
\text { search }\end{array}$ & $\begin{array}{l}\text { Golden-section } \\
\text { search }\end{array}$ & The range of searching \\
\hline$m_{2}\left[\times 10^{3} \mathrm{~kg}\right]$ & 91.980 & 23.428 & 71.665 & \multirow{4}{*}{$\begin{array}{l}\text { From } 0.0 \text { to ratio of } 0.3 \\
\text { from } m_{1}[1]\end{array}$} \\
\hline$m_{3}\left[\times 10^{3} \mathrm{~kg}\right]$ & 65.957 & 23.428 & 57.979 & \\
\hline$m_{4}\left[\times 10^{3} \mathrm{~kg}\right]$ & 29.569 & 23.428 & 22.145 & \\
\hline$m_{5}\left[\times 10^{3} \mathrm{~kg}\right]$ & 82.715 & 23.428 & 22.145 & \\
\hline$k_{2}[\mathrm{kN} / \mathrm{m}]$ & 176.42 & 375.025 & 381.97 & \multirow{2}{*}{ From 0.0 to $500 \mathrm{kN} / \mathrm{m}$} \\
\hline$k_{3}[\mathrm{kN} / \mathrm{m}]$ & 249.81 & 374.925 & 190.98 & \\
\hline$k_{4}[\mathrm{kN} / \mathrm{rad}]$ & 147.84 & 374.925 & 309.02 & From 0.0 to $500 \mathrm{kN} / \mathrm{rad}$ \\
\hline$c_{2}[\mathrm{kN} \cdot \mathrm{s} / \mathrm{m}]$ & 196.10 & 150.025 & 152.79 & From 0.0 to $200 \mathrm{kN} \cdot \mathrm{s} / \mathrm{m}$ \\
\hline$c_{3}[\mathrm{kN} \cdot \mathrm{s} / \mathrm{rad}]$ & 81.878 & 50.075 & 152.79 & From 0.0 to $200 \mathrm{kN} \cdot \mathrm{s} / \mathrm{rad}$ \\
\hline$L[\mathrm{~m}]$ & 6.47 & 7.5 & 2.36 & From 0.0 to $10 \mathrm{~m}$ \\
\hline
\end{tabular}

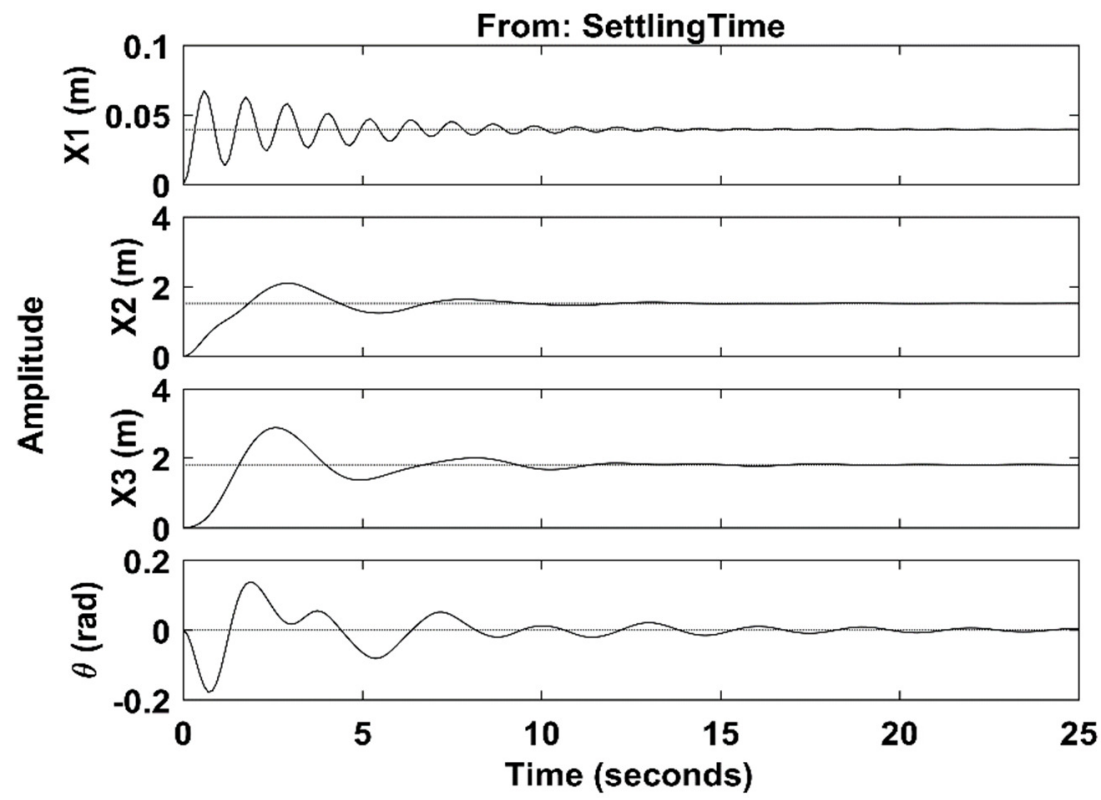

Fig. 2. The amplitude of $x_{1}, x_{2}, x_{3}$ and $\theta$ with time at $a_{g}=0.36 \mathrm{~g}$ for the golden-section search optimization approach 


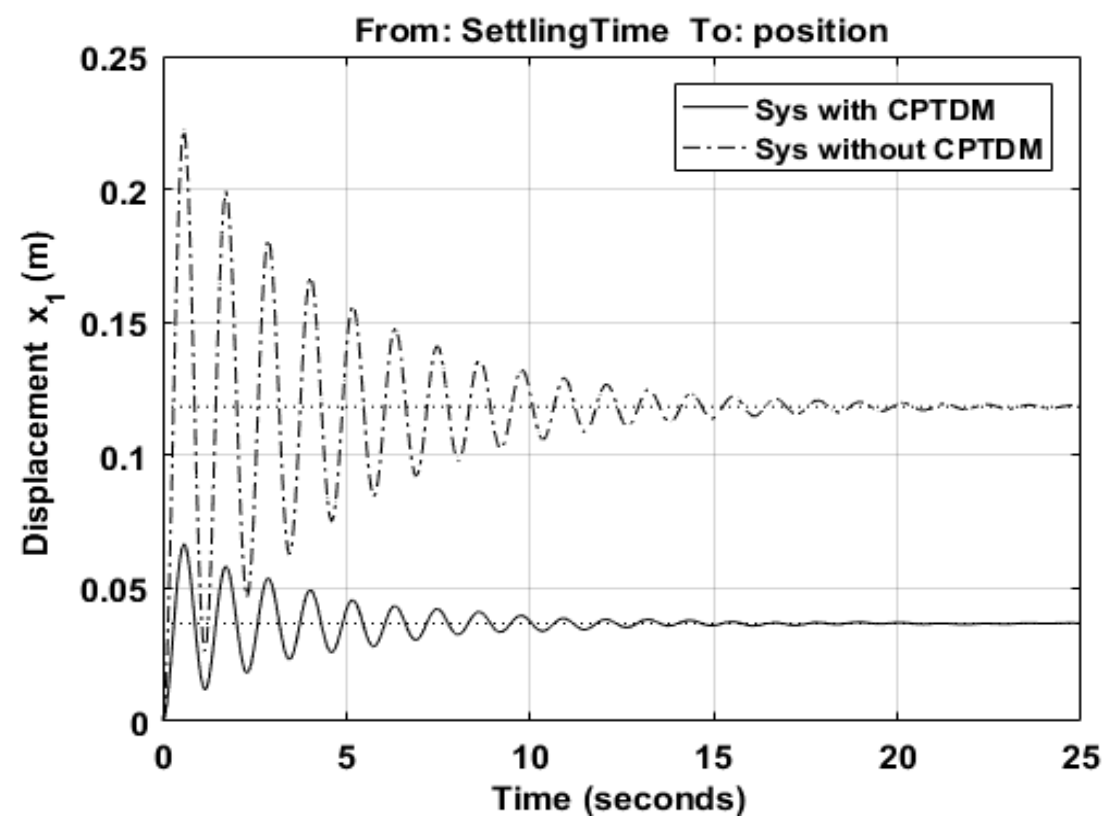

Fig. 3. Comparison of system response with and without the 3-DOF CPTMD at $a_{g}=0.36 \mathrm{~g}$ for the golden-section search optimization approach

\subsection{For extreme earthquake excitation at $a_{g}=3 g$}

When applying a high ground acceleration value typically $\left(a_{g}=3 \mathrm{~g}\right)$, which is induced from an extreme earthquake excitation, the system response is shown in Table 4 using the golden-section search optimization approach.

Table 4. The system response between the golden-section search optimization approach at $a_{g}=3 \mathrm{~g}$

\begin{tabular}{|l|c|}
\hline \multicolumn{1}{|c|}{ Criterion } & Golden-section search \\
\hline Peak amplitude [m] & 0.07 \\
\hline Overshot [\%] & 74.85 \\
\hline Settling time [s] & 16.73 \\
\hline Computational time [s] & 101.44 \\
\hline No. of Iterations & 81 \\
\hline
\end{tabular}

The optimum Parameters' values of the components of the attached 3-DOF CPTMD for the golden-section search optimization approach are shown in Table 5. Again, the golden-section search is demonstrated to be very effective in vibrations dampening. 
Table 5. The optimum Parameters' values of the components of the attached 3-DOF CPTMD for the golden-section search optimization approach at $a_{g}=3 \mathrm{~g}$ for the shown range of searching

\begin{tabular}{|c|c|c|}
\hline Parameters & Golden-section search & The range of searching \\
\hline$m_{2}\left[\times 10^{3} \mathrm{~kg}\right]$ & 5.227 & \multirow{4}{*}{ From 0.0 to ratio of 0.3 from $m_{1}$ [1] } \\
\hline$m_{3}\left[\times 10^{3} \mathrm{~kg}\right]$ & 87.122 & \\
\hline$m_{4}\left[\times 10^{3} \mathrm{~kg}\right]$ & 10.243 & \\
\hline$m_{5}\left[\times 10^{3} \mathrm{~kg}\right]$ & 34.432 & \\
\hline$k_{2}[\mathrm{kN} / \mathrm{m}]$ & 481.84 & \multirow{2}{*}{ From 0.0 to $500 \mathrm{kN} / \mathrm{m}$} \\
\hline$k_{3}[\mathrm{kN} / \mathrm{m}]$ & 269.98 & \\
\hline$k_{4}[\mathrm{kN} / \mathrm{rad}]$ & 454.72 & From 0.0 to $500 \mathrm{kN} / \mathrm{rad}$ \\
\hline$c_{2}[\mathrm{kN} \cdot \mathrm{s} / \mathrm{m}]$ & 195.90 & From 0.0 to $200 \mathrm{kN} \cdot \mathrm{s} / \mathrm{m}$ \\
\hline$c_{3}[\mathrm{kN} \cdot \mathrm{s} / \mathrm{rad}]$ & 188.93 & From 0.0 to $200 \mathrm{kN} \cdot \mathrm{s} / \mathrm{rad}$ \\
\hline$L[\mathrm{~m}]$ & 3.63 & From 0.0 to $10 \mathrm{~m}$ \\
\hline
\end{tabular}

It is observed from Figure 4 that the amplitude of the maximum value of the swinging angle $(\theta)$ of the pendulum is approximately $\left(0.1 \mathrm{rad}=5.73^{\circ}\right)$ and diminished with time. This agrees very well with the assumptions made in equation (9).

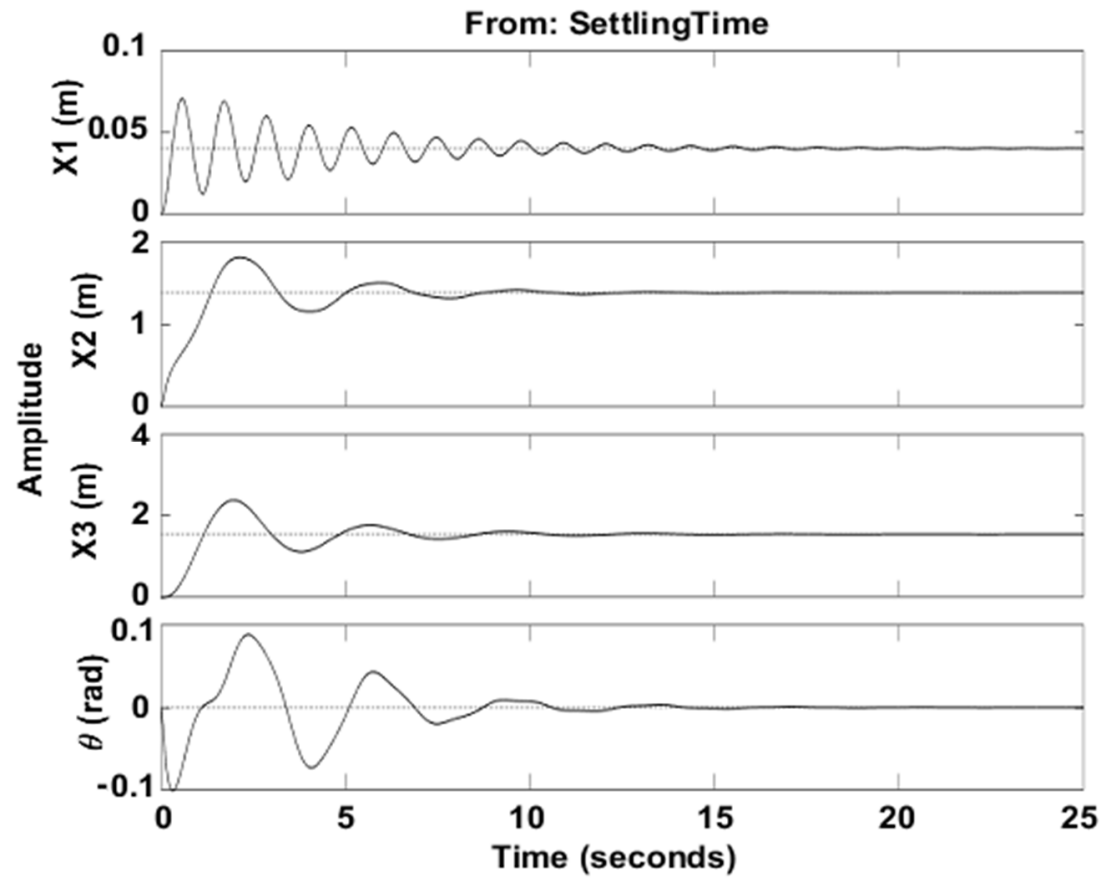

Fig. 4. The amplitude of $x_{1}, x_{2}, x_{3}$, and $\theta$ with time at $a_{g}=3 \mathrm{~g}$ for the golden-section search optimization approach 
Figure 5 shows that after using the golden-section search method and its optimum values for the attached 3-DOF CPTMD, the peak amplitude of the main structure reduced from $1.85 \mathrm{~m}$ which is considered fatal and destroyable for the main platform structure, to only $0.07 \mathrm{~m}$ with a percentage reduction of nearly $96.2 \%$ which demonstrates the importance and the effectiveness of using the proposed solution in effectively attenuating the vibrations of the oil recovery offshore jacket platform.

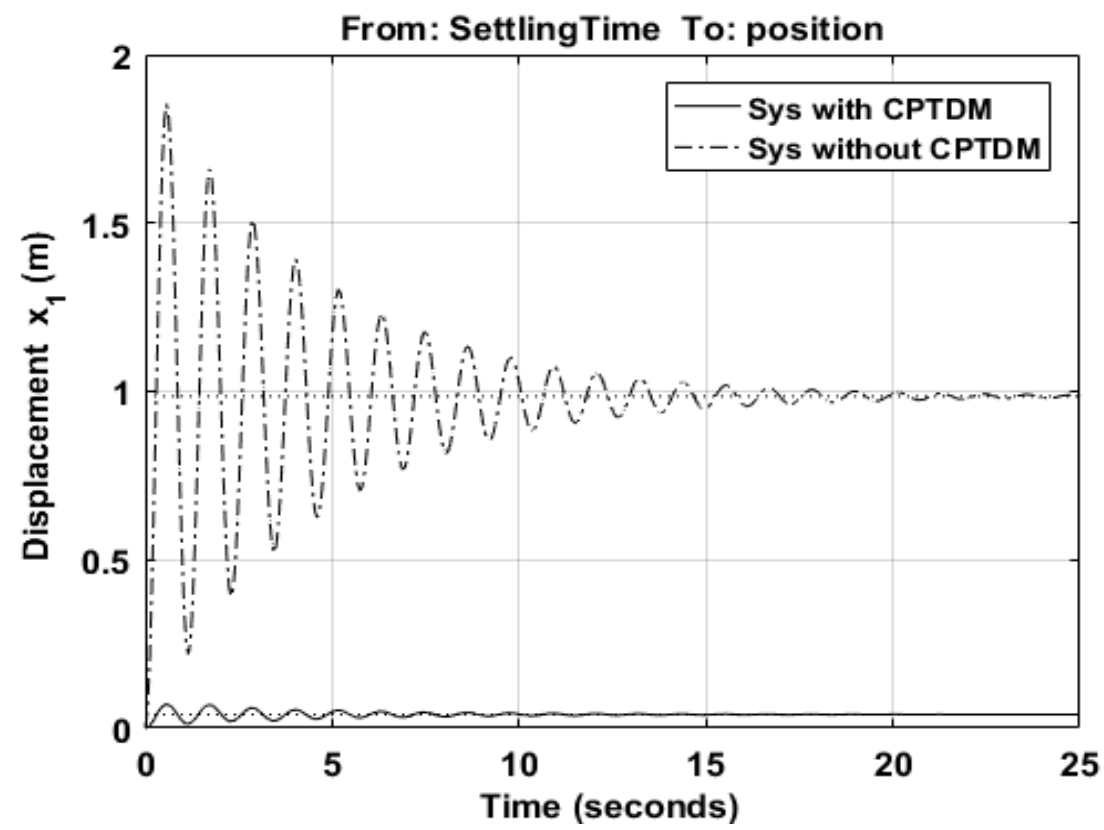

Fig. 5. Comparison of system response with and without the 3-DOF CPTMD at $a_{g}=3 \mathrm{~g}$ for the golden-section search optimization approach

\section{Conclusions}

Modelling and simulation of a SDOF structure, which is an offshore platform equipped with a 3-DOF CPTMD, are carried out in this research. The offshore platform is excited by mild and extreme earthquakes. Additionally, three search optimization techniques were used to find the optimum values of the system parameters, and the golden-section search was the optimum one. The ability of the platform to reduce the oscillation soared after attaching the 3-DOF CPTMD, and the percentage reduction in peak amplitude for the mild and the extreme excitations are 70 and $96.2 \%$, respectively. In conclusion, the obtained results have revealed that the proposed 3-DOF CPTMD proved to be effective in attenuating the platform vibrations. 


\section{References}

[1] Hadi, M.N., \& Arfiadi, Y. (1998). Optimum design of absorber for MDOF structures. Journal of Structural Engineering, 124(11), 1272-1280.

[2] Xue, Q., Zhang, J., He, J., \& Zhang, C. (2016). Control performance and robustness of pounding tuned mass damper for vibration reduction in SDOF structure. Shock and Vibration, 2016.

[3] Hoang, N., Fujino, Y., \& Warnitchai, P. (2008). Optimal tuned mass damper for seismic applications and practical design formulas. Engineering Structures, 30(3), 707-715.

[4] Chen, Z., Fang, H., Han, Z., \& Sun, S. (2019). Influence of bridge-based designed TMD on running trains. Journal of Vibration and Control, 25(1), 182-193.

[5] Lackner, M.A., \& Rotea, M.A. (2011). Passive structural control of offshore wind turbines. Wind Energy, 14(3), 373-388.

[6] Longarini, N., \& Zucca, M. (2014). A chimney's seismic assessment by a tuned mass damper. Engineering Structures, 79, 290-296.

[7] Wang, W., Dalton, D., Hua, X., Wang, X., Chen, Z., \& Song, G. (2017). Experimental study on vibration control of a submerged pipeline model by eddy current tuned mass damper. Applied Sciences, 7(10), 987.

[8] Yingling, A.J., \& Agrawal, B.N. (2014). Applications of tuned mass dampers to improve performance of large space mirrors. Acta Astronautica, 94(1), 1-13.

[9] Yang, J.N., Agrawal, A.K., Samali, B., \& Wu, J.-C. (2004). Benchmark problem for response control of wind-excited tall buildings. Journal of Engineering Mechanics, 130(4), 437-446.

[10] Rana, R., \& Soong, T. (1998). Parametric study and simplified design of tuned mass dampers. Engineering Structures, 20(3), 193-204.

[11] Zuo, L., \& Nayfeh, S.A. (2004). Minimax optimization of multi-degree-of-freedom tuned-mass dampers. Journal of Sound and Vibration, 272(3-5), 893-908.

[12] Pourzeynali, S., Lavasani, H., \& Modarayi, A. (2007). Active control of high rise building structures using fuzzy logic and genetic algorithms. Engineering Structures, 29(3), 346-357.

[13] Hrovat, D., Barak, P., \& Rabins, M. (1983). Semi-active versus passive or active tuned mass dampers for structural control. Journal of Engineering Mechanics, 109(3), 691-705.

[14] Symans, M.D., \& Constantinou, M.C. (1999). Semi-active control systems for seismic protection of structures: a state-of-the-art review. Engineering Structures, 21(6), 469-487.

[15] Lazar, I., Neild, S., \& Wagg, D. (2014). Using an inerter-based device for structural vibration suppression. Earthquake Engineering \& Structural Dynamics, 43(8), 1129-1147.

[16] Li, C. (2000). Performance of multiple tuned mass dampers for attenuating undesirable oscillations of structures under the ground acceleration. Earthquake Engineering \& Structural Dynamics, 29(9), 1405-1421.

[17] Ata, A.A., \& Kamel, A.G. (2019). Modelling and simulation of a combined pendulum tuned mass damper attached to a vibrating system. Proceedings of the 5th International Conference on Mechatronics and Robotics Engineering, 23-27.

[18] Ata, A.A., \& Kamel, A. G. (2018). Numerical evaluation of the effect of combined pendulum tuned mass damper on a basic vibrating system. International Journal of Mechatronics and Applied Mechanics, (4), 270-279.

[19] Han, S.M., \& Benaroya, H. (2002). Nonlinear and Stochastic Dynamics of Compliant Offshore Structures. (98). Springer Science \& Business Media.

[20] Asad, S., Salahat, M., Zalata, M.A., Alia, M., \& Al Rawashdeh, A. (2011). Design of fuzzy PD-controlled overhead crane system with anti-swing compensation. Journal of Engineering and Computer Innovations, 2(3), 51-58. 
[21] Marian, L., \& Giaralis, A. (2014). Optimal design of a novel tuned mass-damper-inerter (TMDI) passive vibration control configuration for stochastically support-excited structural systems. Probabilistic Engineering Mechanics, 38, 156-164.

[22] Takewaki, I. (2011). Preliminary report of the 2011 off the Pacific coast of Tohoku Earthquake. Journal of Zhejiang University-Science A, 12(5), 327-334.

[23] Kiefer, J. (1953). Sequential minimax search for a maximum. Proceedings of the American Mathematical Society, 4(3), 502-506.

[24] Wilde, D.J. (1964). Optimum Seeking Methods. Prentice Hall.

[25] Brent, R.P. (1973). Algorithms for Minimization without Derivatives. Englewood Cliffs, New Jersey: Prentice-Hall. 